\title{
A prospective randomized comparison of the minimally invasive direct anterior and the transgluteal approach for primary total hip arthroplasty
}

Johannes C. Reichert ${ }^{1,2^{*}}$ D, Eberhard von Rottkay ${ }^{2}$, Franz Roth ${ }^{1}$, Tim Renz ${ }^{1}$, Johannes Hausmann ${ }^{1}$, Julius Kranz ${ }^{1}$, Lars Rackwitz ${ }^{2}$, Ulrich Nöth ${ }^{1,2}$ and Maximilian Rudert ${ }^{1}$

\begin{abstract}
Background: The presented prospective randomized controlled single-centre study compares the clinical outcome up to 12 months after total hip arthroplasty using a minimally invasive single-incision direct anterior (DAA) and a direct transgluteal lateral approach.

Methods: A total of 123 arthroplasties were evaluated utilizing the Harris Hip Score (HHS), the extra short musculoskeletal functional assessment questionnaire (XSFMA), the Short Form 36 (SF-36) health survey, a Stepwatch ${ }^{\text {TM }}$ Activity Monitor (SAM), and a timed $25 \mathrm{~m}$ foot walk (T25-FW). Postoperative $x$-ray images after THA were reviewed to determine inclination and stem positioning.

Results: At final follow-up, the XSFMA functional index scores were 10.3 (anterior) and 15.08 (lateral) while the bother index summed up to a score of 15.8 (anterior) and 21.66 (lateral) respectively, thus only differing significantly for the functional index ( $p=0.040$ and $p=0.056$ ). The SF-36 physical component score (PCS) was 47.49 (anterior) and 42.91 (lateral) while the mental component score (MCS) summed up to 55.0 (anterior) and 56.23 (lateral) with a significant difference evident for the PCS $(p=0.017 ; p=0.714)$. Patients undergoing THA through a DAA undertook a mean of 6402 cycles per day while those who had undergone THA through a transgluteal approach undertook a mean of 5340 cycles per day $(p=0.012)$. Furthermore, the obtained outcome for the T25-FW with $18.4 \mathrm{~s}$ (anterior) and $19.75 \mathrm{~s}$ (lateral) and the maximum walking distance $(5932 \mathrm{~m}$ and $5125 \mathrm{~m})$ differed significantly $(p=0.046$ and $p$ $=0.045$ ). The average HHS showed no significant difference equaling 92.4 points in the anterior group and 91.43 in the lateral group $(p=0.477)$. The radiographic analysis revealed an average cup inclination of $38.6^{\circ}$ (anterior) and 40 . $28^{\circ}$ (lateral) without signs of migration.
\end{abstract}

Conclusion: In summary, our outcomes show that after 1 year THA through the direct anterior approach results in a higher patient activity compared to THA utilizing a transgluteal lateral approach while no differences regarding hip function are evident.

Trial registration: DRKS00014808 (German Clinical Trial Register DRKS); date of registration: 31.05.2018.

Keywords: Total hip arthroplasty, Direct anterior approach, Minimally invasive, Transgluteal approach, Prospective study

\footnotetext{
* Correspondence: johannes.c.reichert@googlemail.com

${ }^{1}$ Department of Orthopaedic Surgery, König-Ludwig-Haus, Center for

Musculoskeletal Research, Julius-Maximilians-University, Brettreichstraße 11,

97074 Würzburg, Germany

${ }^{2}$ Department of Orthopaedic and Trauma Surgery, Evangelisches

Waldkrankenhaus Spandau, Stadtrandstrasse 555, 13589 Berlin, Germany
}

(c) The Author(s). 2018 Open Access This article is distributed under the terms of the Creative Commons Attribution 4.0 International License (http://creativecommons.org/licenses/by/4.0/), which permits unrestricted use, distribution, and

reproduction in any medium, provided you give appropriate credit to the original author(s) and the source, provide a link to the Creative Commons license, and indicate if changes were made. The Creative Commons Public Domain Dedication waiver (http://creativecommons.org/publicdomain/zero/1.0/) applies to the data made available in this article, unless otherwise stated. 


\section{Background}

Total hip arthroplasty (THA) can generally be seen as a very successful procedure in the field of orthopaedics [1]. The demand for THA and especially minimally invasive surgeries (MIS) is continuously increasing [2] as successful THA results in pain relief and restored joint functionality allowing a higher degree of patient activity and therefore quality of life [3]. Minimally invasive THA is most commonly performed utilizing the direct anterior (DAA), the anterolateral and the posterior approach to the hip. MIS is associated with less blood loss [4], decreased perioperative pain levels, and faster recovery [3, 5]. However, there is still ample debate whether early functional outcomes differ using the DAA or a standard lateral approach [6].

Consequently, the primary aim of the present randomized controlled single-centre study was to prospectively compare the functional outcome, as measured by the HHS and SAM, between patients undergoing minimally invasive THA through a DAA with those undergoing THA through a conventional transgluteal approach. Secondary aims included comparison of the XSMFA (functional and bother index), a timed $25 \mathrm{~m}$ foot walk (T25-FW), and the short-form 36 questionnaire (SF-36 mental and physical).

\section{Methods}

The present investigator sponsored, prospective randomized controlled single-centre study was approved by the ethics committee of the medical faculty of the University of Würzburg (approval number 72/11) and compares two different surgical techniques, the minimally invasive DAA as described by Rachbauer [7] and the lateral transgluteal approach according to Bauer et al. [8]. The DAA was introduced in our orthopaedic department in 2008 as a routine approach for THA. Prior to 2008 the transgluteal approach was predominately used. An a priori power analysis using $G^{*}$ Power 3 was performed to determine the necessary sample size $N$ for a two-sample $\mathrm{t}$ test of independent variables given an $\alpha$ error probability of 0.05 , a desired power level of 0.8 (1- $\beta$ ), and a medium effect size of 0.5 . The required $N$ was calculated to be 60 per group. With a power level of 0.9 a total of 81 patients would have been required in each group. The study was powered to detect a 500 step difference in measurements obtained with the SAM at a single time point assuming an average of 5500 steps/day and a standard deviation of 1000. A significance level of $5 \%$ was chosen.

The SAM (StepWatch Activity Monitor, Orthocare Innovations, 6405 218th St SW, Suite 100, Mountlake Terrace, WA 98043-2180, US) is an example of an accelerometer based activity monitor that has been used widely in different population groups. The SAM is small
$(75 \times 50 \times 20 \mathrm{~mm})$ and lightweight $(38 \mathrm{~g})$ and is worn at the ankle. The monitor contains a custom sensor that uses a combination of acceleration, position, and timing to detect steps. Thus the outputs of the SAM are based on the amount, rate, and pattern of walking. The SAM is calibrated based on each individual's height and gait pattern. Reported intraclass correlation coefficients (ICCs) for mean steps/day range from 0.86 to 0.99 representing an excellent test-retest reliability, and 95\% limits of agreement of less than 40\% [9].

Accounting for an expected drop out rate of $15 \%$ a number of 69 patients was planned to be recruited for each study arm. Between November 2011 and March 2014148 consecutive patients were enrolled and allocated to the treatment groups by the principal investigator utilizing a computer generated block randomization list as described previously [10]. Block randomization is a commonly used technique to reduce bias and achieve balance in the allocation of participants to treatment arms. It increases the probability that each arm will contain an equal number of individuals by sequencing participant assignments by block. It was not possible to blind the patient for the allocated surgical technique, as the surgical incision site of the studied approaches was different.

Four patients were lost to follow up in the anterior group whereas 21 individuals dropped out of the lateral group leaving 73 (anterior) and 50 (lateral) complete data sets for analysis respectively. The main reason for dropout was a lack of time, 3 patients had moved away, two patients were diagnosed with a malignant disease and two patients had to be excluded by hindsight not meeting the radiologic inclusion criteria (Fig. 1).

A high rate of eligible patients declined trial participation as they explicitly asked for THA through a minimally invasive direct anterior approach.

Eight experienced, fellowship-trained surgeons performed the surgeries (Table 1).

Patients with primary osteoarthritis scheduled for cemented or non-cemented THA were enrolled following defined inclusion and exclusion criteria.

Exclusion criteria were an age $<40$ or $>80$ years, a Body-Mass-Index $(\mathrm{BMI})>35 \mathrm{~kg} / \mathrm{m}^{2}$; hip dysplasia or a congenital disorder of the hip, former osteotomies of hip, knee or pelvis; an impairment of the contralateral side or osteoarthritis of the ipsilateral knee, osteoporosis, degenerative spine disease, or a severe systemic disease (ASA-Score $\geq 4$, malignant or cardiovascular disease).

The overall patient drop out and higher rate of patients lost to follow-up due to a lack of time and interest in the lateral group is considerable. However, both patient cohorts did not differ significantly after randomization regarding gender, age, BMI, educational and socioeconomic status, or any other specific patient 


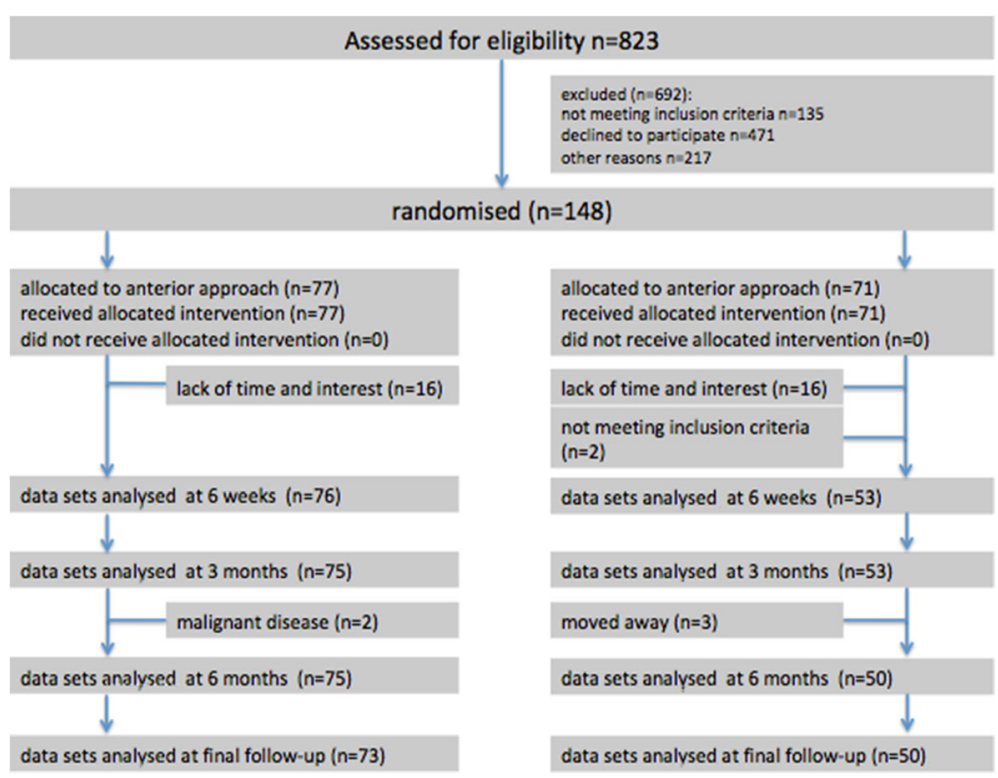

Fig. 1 Flow diagram of the progress through the phases of the randomised trial

characteristics thus contesting a general problem with randomization. As well, at baseline, completers did not differ from patients lost to follow-up.

The selected commercially available implants included Trilogy or Allofit cups (Trilogy Acetabular Hip System; Allofit ${ }^{\circ}$ Acetabular Cup System), the non-cemented M/ L-Taper stem or the cemented M. E. Müller straight stem (all Zimmer). Overall, the anterior group included 4 , the lateral group 5 cemented stems.

For all patients participating in the trial we applied established standardized treatment protocols, which included a multimodal pain management and rapid rehabilitation.
Patient examinations were carried out by a qualified physician 6 weeks prior to surgery and 6 weeks, 3, 6 and 12 months after surgery.

Activity was evaluated using the Stepwatch ${ }^{\text {tw }}$ Activity Monitor (SAM) as the primary outcome measure (Orthocare Innovations, Oklahoma City, OK, USA) over a period of 7 days (preoperatively, 3 and 12 months after surgery) to calculate a daily average number of cycles [9].

Secondary outcome measures included the Harris hip score (HHS) [11] as an important clinical measure to evaluate hip function and the reciprocal extra short musculoskeletal functional assessment questionnaire

Table 1 Characteristics of evaluated patient collective preoperatively and at final follow-up

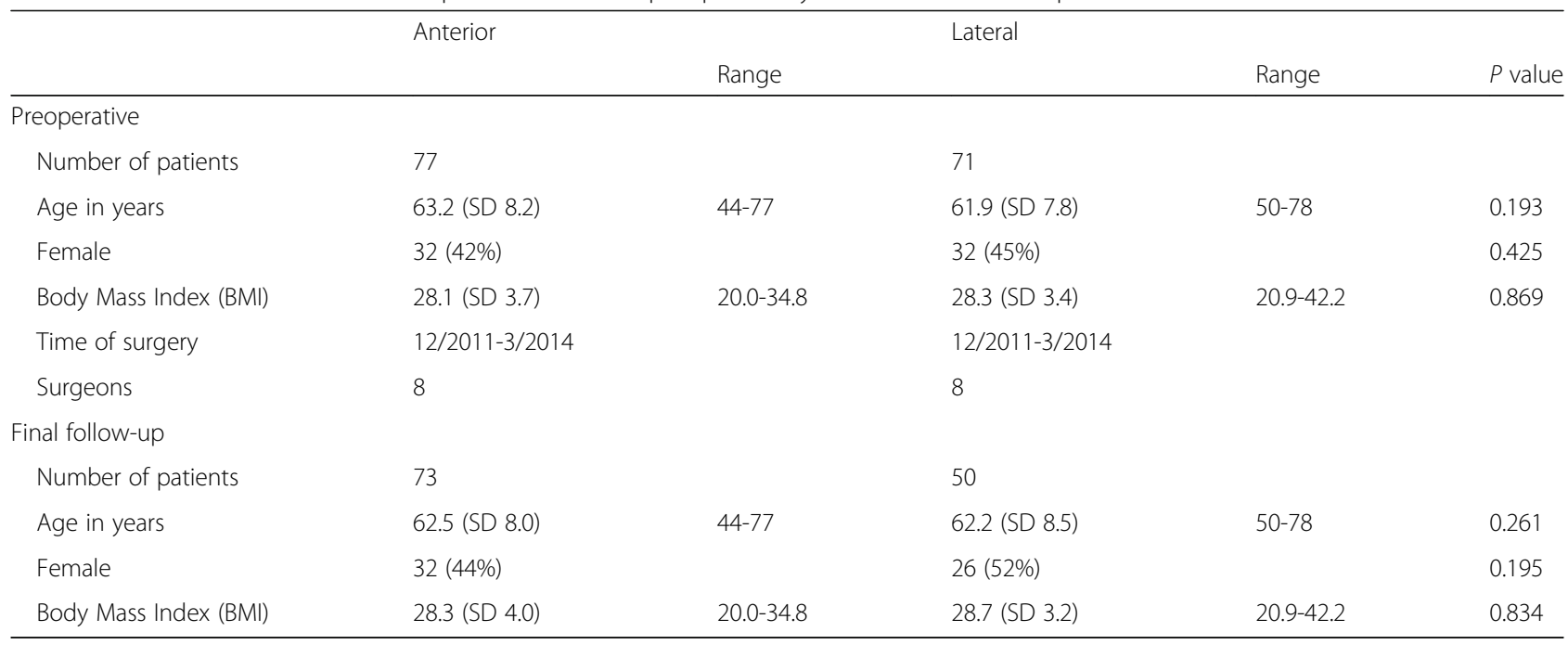


(XSMFA functional and bother index, 16 items) [12]. The domains covered by the HHS are pain, function, absence of deformity and range of motion. The HHS includes ten items and has a maximum score of 100 representing the best possible outcome. Additional secondary measures were a timed $25 \mathrm{~m}$ foot walk (T25-FW), and a visual analogue scale (VAS, range 110) to further characterize patient activity. The individual patient health status was monitored using the short-form 36 questionnaire (SF-36 mental and physical component summaries) [13].

Conventional $\mathrm{x}$-ray projections of the pelvis (anterior-posterior, frog leg view) were used to assess bony implant integration, cup inclination, and stem orientation (valgus, neutral or varus) as described previously by Johnston et al. [14]. Two independent observers performed the assessment. At the time of follow-up, clinical examination was performed for all patients, respectively.

Source data verification was conducted by the study team. After regular trial termination, acquired data was tested for normal distribution using both the Kolmogorov-Smirnov and Shapiro-Wilk test. In case of normally distributed dependent variables the two-tailed t-test was used for between group comparisons, the Mann-Whitney-U test for non-parametric data.

The non-parametric Friedman test was chosen to analyse repeated measures within the two patient groups. As a post hoc test, the Wilcoxon signed-rank test was used and a Bonferroni adjustment made. Statistical analysis was carried out using SPSS 19.0 (IBM, Ehningen, Germany), and $p$-values $<0.05$ were considered significant.

\section{Results}

In total, 77 arthroplasties were preformed through the minimally invasive DAA and 71 arthroplasties using the transgluteal lateral approach. The enrolment of more than 69 patients was allowed to possibly compensate for a drop out of more than nine patients per group.

Daily activity as determined by the StepWatch ${ }^{\mathrm{Tm}}$ activity monitor resulted in an average of 4695 recorded load cycles per day preoperatively, 5992 (anterior) and 5239 (lateral) after 3 months, and 6402 and 5340 recorded load cycles after 1 year, respectively. The preoperatively recorded load cycles were pooled, as no statistical difference was determined between the groups $(p=0.489)$. Both 3 and 12 months after surgery, the patients operated using the direct anterior approach showed a significantly higher number of steps per day $(p=0.035$ and $p$ $=0.012$ ) (Table 2). For the anterior group a significant increase was observed at final follow up $(p<0.001)$ compared to preoperative values and between month 3 and $12(p=0.047)$ while no significant change over time was seen for the lateral group (Table 3).

The average HHS revealed very good clinical results. Compared to preoperative scores a significant increase was seen 6 weeks postoperatively $(\mathrm{p} \leq 0.001)$ and again between 6 weeks and 3 months $(p=0.039$, Table 4) for both groups. No significant difference between the two surgical approaches was determined at any time point equalling 92.4 points in the anterior group and 91.4 in the lateral group 12 months after surgery $(p=$ 0.477)(Table 5). Moreover, no statistically significant differences were found for the different domains of the HHS.

In comparison to the preoperative scores (35.2, SD 16.1 and 40.5, SD 16.0, $p=0.053$ ) the average functional index of the reciprocal XSFMA decreased significantly 6 weeks postoperatively. Again a significant decrease was seen between 6 weeks and 3 months for both groups and between month 3 and 6 for the lateral group to result in a score of 10.3 (SD 13.0) 12 months after THA using the anterior approach and 15.1 (SD 16.3) using the lateral approach (Table 6). After 6 weeks as well as 3 and 12 months postoperatively patients who had received THA over an anterior approach achieved significantly better XSMFA functional indices when compared to patients of the lateral group. No significant difference between the groups was determined at baseline and the 6 months time point (Table 7).

For the obtained bother indices no significant difference was found between the groups at any time point (Table 7). The preoperative bother index equalled 48.7 (SD 20.5, anterior) and 53.0 (SD 17.9, lateral) and significantly improved to 15.8 (SD 18.0, anterior) and 21.66 (SD 19.55, lateral) after 12 months. The increase after 6

Table 2 Comparison of StepWatch activity monitor outcomes at each time point

\begin{tabular}{|c|c|c|c|c|c|}
\hline \multirow{2}{*}{$\begin{array}{l}\text { StepWatch } \\
\text { Approach }\end{array}$} & \multicolumn{2}{|l|}{ Mean (SD) } & \multicolumn{2}{|l|}{$95 \% \mathrm{Cl}$} & \multirow[t]{2}{*}{$P$ value } \\
\hline & Anterior & Lateral & Anterior & Lateral & \\
\hline \multicolumn{6}{|l|}{ Time points } \\
\hline preoperative & 4695 (1177) & 4695 (1177) & $4507-4887$ & $4507-4887$ & n.a. \\
\hline 3 months & $5992(2170)$ & 5239 (2309) & $5501-6483$ & $4617-5861$ & $0.035^{\mathrm{a}}$ \\
\hline 12 months & $6402(2523)$ & $5340(1887)$ & $5823-6981$ & $4817-5863$ & $0.012^{a}$ \\
\hline
\end{tabular}

$S D$ standard deviation, $\mathrm{Cl}$ confidence interval

${ }^{a}$ Mann-Whitney-U test 
Table 3 Within group comparison of StepWatch activity monitor outcomes over time

\begin{tabular}{llllll}
\hline & Mean (SD) & & $P$ value & $P$ value \\
StepWatch & Preoperative & 3 months & & 12 months \\
\hline Approach \\
Anterior & $4695(1177)$ & $5992(2170)$ & $0.078^{\text {a }}$ & $6402(2523)$ & $0.047^{\text {a }}$ \\
Lateral & $4695(1177)$ & $5239(2309)$ & $1.00^{\text {a }}$ & $5340(1887)$ & $1.00^{\text {a }}$ \\
\hline $\begin{array}{l}\text { SD standard deviation } \\
\text { a Friedman test }\end{array}$ & & & &
\end{tabular}

weeks compared to preoperative values was significant for both groups $(p<0.001)$, furthermore a significant increase was determined between 6 weeks and 3 months ( $p=0.005$ anterior; $p=0.021$ lateral) (Table 6).

For the timed $25 \mathrm{~m}$ foot walk (T25-FW) the results after 6 weeks were significantly better compared to preoperative measurements in both groups $(p=0.038$, anterior; $p=0.041$, lateral), furthermore a significant increase was determined between 6 weeks and 3 months $(p=0.043$ anterior; $p=0.045$ lateral) (Table 6). The between group comparison showed no significant difference preoperatively and 6 and 12 weeks after intervention. However, 6 and 12 months after surgery, the patients in the anterior group showed significantly better results averaging $18.3 \mathrm{~s}$ (SD 4.1, anterior) compared to $19.9 \mathrm{~s}$ (SD 5.53, lateral, $p=0.040$ ) and $18.1 \mathrm{~s}$ (SD 3.4, anterior) versus 19.8 (SD 4.6, lateral, $p=0.046$ ) (Table 7).

Activity levels as assessed by the patients on a visual analogue scale (range 1-10) showed no significant difference preoperatively with 5.0 (SD 1.85, anterior) and 4.9 (SD 1.80, lateral) points $(p=0.577)$. Similar results were obtained after 6 weeks (6.9, SD 1.92 and 6.8, SD 2.90; $p$ $=0.75$ ). After 3 months, however, the patients of the anterior group described significantly higher activity levels (7.3, SD 1.65 and 6.8 SD 1.35; $p=0.032$ ), which were confirmed at the final follow-up (7.5, SD 1.82 and 7.0, SD 1.57, $p=0.016$ ) (Table 7). For both cohorts, the outcome 6 weeks after surgery was significantly better compared to preoperative measurements (each $p<0.001$ ) (Table 6).

In addition the patients of the anterior group reported a significantly higher maximum walking distance before the onset of pain with an average of $6435 \mathrm{~m}$ (SD 4260)
Table 5 Between group comparison of the HHS at each time point

\begin{tabular}{llllllll}
\hline HHS & \multicolumn{2}{l}{ Mean (SD) } & & $95 \% \mathrm{Cl}$ & $P$ value \\
\cline { 2 - 3 } Approach & Anterior & Lateral & & Anterior & Lateral & \\
\hline Time points & & & & & \\
$\quad$ Preoperative & $54.0(14.2)$ & $53.0(15.7)$ & $50.8-57.2$ & $49.4-56.7$ & $0.281^{\text {a }}$ \\
6 weeks & $81.6(12.1)$ & $82.4(12.0)$ & $78.3-83.7$ & $78.8-85.2$ & $0.068^{\text {a }}$ \\
3 months & $89.8(9.3)$ & $88.4(9.9)$ & $86.9-91.1$ & $85.3-90.7$ & $0.370^{\text {a }}$ \\
6 months & $90.3(9.8)$ & $89.1(10.0)$ & $87.8-92.2$ & $86.2-91.8$ & $0.556^{\text {a }}$ \\
12 months & $92.4(8.6)$ & $91.4(9.1)$ & $90.3-94.0$ & $88.5-93.5$ & $0.477^{\text {a }}$ \\
\hline
\end{tabular}

$S D$ standard deviation, $\mathrm{Cl}$ confidence interval

${ }^{a}$ Mann-Whitney-U test

compared to $5125 \mathrm{~m}$ (SD 3868, $p=0.045$, Table 7) at final follow-up.

The average scores obtained in the physical component of the SF-36 (PCS) were calculated to be 27.5 (SD 8.5, anterior) and 26.7 (SD 8.6, lateral) points preoperatively, significantly increasing to 39.7 (SD 9.7) and 37.8 (SD 9.99) 6 weeks after surgery $(p<0.001)$. Between weeks 6 and 12 after surgery again a significant increase to 44.6 (SD 9.16) and 43.1 (SD 9.72) was determined ( $p$ $<0.001, p=0.001)$. The score after 6 months summed up to 46.0 (SD 10.0) and 44.8 (SD 9.95) finally resulting in 47.5 (SD 9.9) and 45.7 (SD 10.9) points 12 months postoperatively. The increase between the 3 and 12 month outcome was again statistically significant $(p=$ 0.041 and $p=0.043$ ) (Table 6). At each postoperative time point the patients in the anterior group achieved significantly higher scores $(p=0.04, p=0.031, p=0.042$ and $p=0.017$ ) (Table 7). The mental component (MCS) summed up to a score of 57.2 (SD 8.4, anterior) and 56.3 (SD 9.2, lateral) before surgery. The MCS did not change significantly over time (Tables 6 and 7).

Generally postoperative pain reduction was assessed to be good to very good. Pain intensity measurements revealed that as early as 6 months after surgery 94\% (anterior) and 96\% (lateral) of all patients were free of pain sensations.

The radiographic analysis revealed an average cup inclination of $38.6^{\circ}$ (SD 5.7) in the anterior group compared to $40.3^{\circ}$ (SD 6.2) in the lateral approach group (Table 8). None of the cups in either group presented with evidence of migration after 1 year.

Table 4 Within group comparison of the HHS over time

\begin{tabular}{|c|c|c|c|c|c|c|c|c|c|}
\hline & Mean (SD) & & $P$ value & & $P$ value & & $P$ value & & $P$ value \\
\hline $\mathrm{HHS}$ & preoperative & 6 weeks & & 3 months & & 6 months & & 12 months & \\
\hline \multicolumn{10}{|l|}{ Approach } \\
\hline Anterior & $54.0(14.2)$ & $81.6(12.1)$ & $<0.001^{\mathrm{a}}$ & $89.8(9.3)$ & $0.039^{a}$ & $90.3(9.8)$ & $1.000^{\mathrm{a}}$ & $92.4(8.6)$ & $0.671^{\mathrm{a}}$ \\
\hline Lateral & $53.0(15.7)$ & $82.4(12.0)$ & $<0.001^{\mathrm{a}}$ & $88.4(9.9)$ & $<0.001^{\mathrm{a}}$ & $89.1(10.0)$ & $1.000^{\mathrm{a}}$ & $91.4(9.1)$ & $0.526^{\mathrm{a}}$ \\
\hline
\end{tabular}

SD standard deviation

${ }^{a}$ Friedman test 
Table 6 Within group comparison of the secondary outcome measures over time

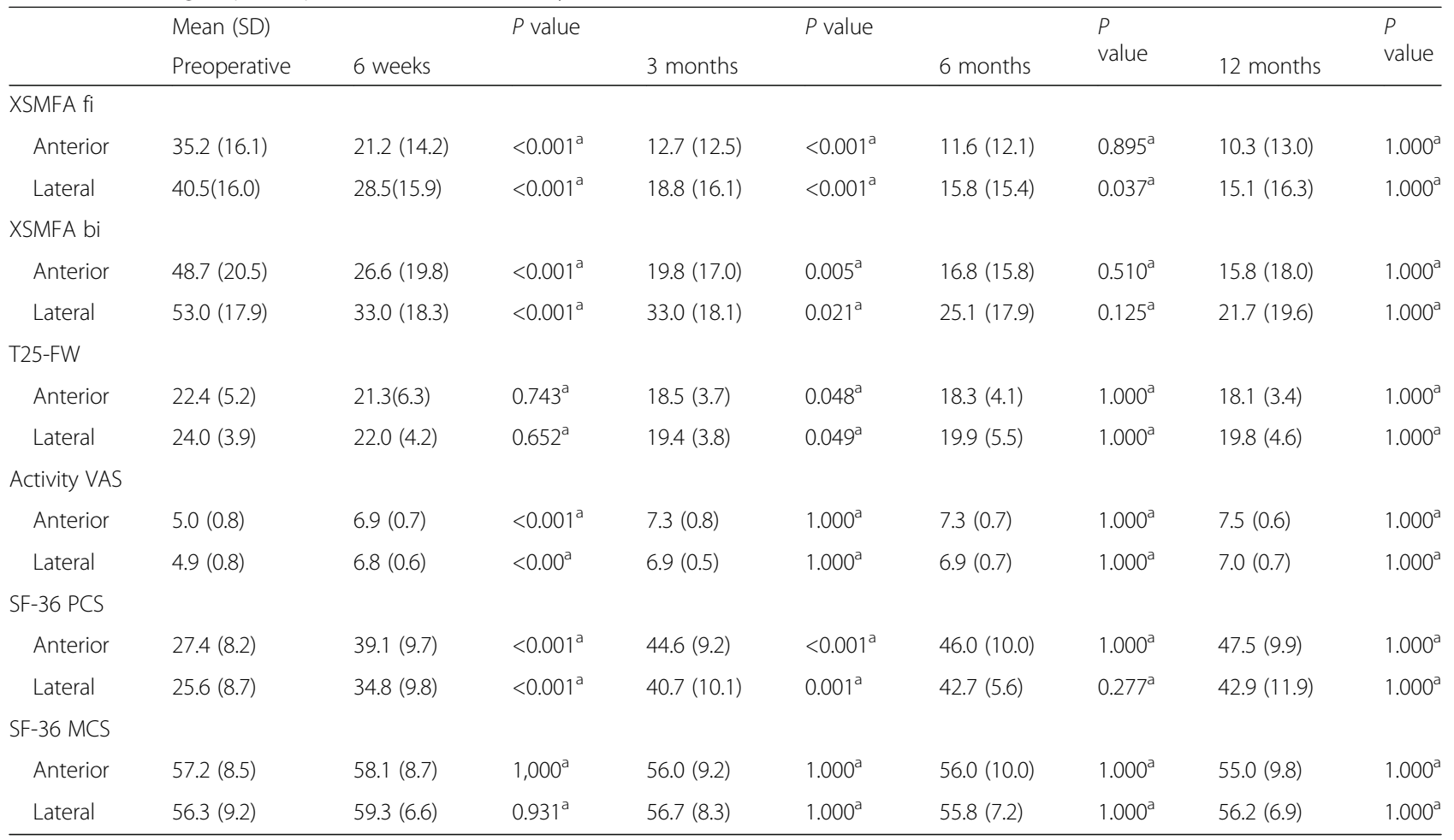

SD standard deviation

${ }^{a}$ Friedman test

Stems positioning was assessed to be neutral in $92.5 \%$ (anterior) and 94\% (lateral) of all cases while 5.5\% (anterior) and $4 \%$ (lateral) were graded varus. A valgus stem orientation was found in $2 \%$ of cases in both groups.

In case of non-cemented THA, all implanted cups and stems showed radiographic evidence of osseointegration, regardless of the approach used.

Peri- and postoperative complications with THA trough the DAA were as follows: We observed three cases of lateral femoral cutaneous nerve (LFCN) palsy and performed one revision surgery due to aseptic loosening. All LFCN deficits had resolved spontaneously at final follow-up. Furthermore, a positive Trendelenburg sign indicative of gluteal insufficiency was observed in one patient. In addition, two leg length discrepancies > $1 \mathrm{~cm}$ occurred. These were clinically relevant and treated with orthopaedic insoles. In the lateral group one joint dislocation occurred, which was treated conservatively, moreover three leg length discrepancies compensated for with insoles, and one gluteal insufficiency.

\section{Discussion}

The demand for minimally invasive hip arthroplasty is continuously increasing [15]. Literature provides evidence for a decreased intra-operative blood loss, lower postoperative pain levels and a shorter recovery time in case of minimally invasive surgery [3-5]. The functional mid-term and long-term outcomes after THA using minimally invasive techniques are comparable with those of THA via standard approaches [16, 17]. The number of randomized trials to underline these findings, however, is still scarce. Consequently, we initiated a prospective randomized study comparing the minimally invasive DAA and standard transgluteal approach.

This study compared outcomes in 73 patients undergoing minimally invasive THA through a DAA with those in 50 patients undergoing THA through a direct lateral approach showed comparable or even superior functional outcomes and activity levels of the anterior approach group as evaluated by the HHS, XSFMA, SF-36, SAM, and T25-FW. The results obtained for both groups are within the expected range and similar to those reported in previous studies [18-20].

Functionality as represented by the HHS did not reveal a significant difference while obtained XSMFA functional indices differed significantly. Overall, our study results are in line with previous reports on minimal-invasive hip replacement [21, 22]. The differing outcome comparing the HHS and XSMFA, however, may find its reason in the different weightings of these scores. The subdivisions of the HHS are pain, functionality and deformities while the XSMFA is composed of two indices (functionality and bother) only. Moreover, 
Table 7 Between group comparison of the secondary outcome measures at each time point

\begin{tabular}{|c|c|c|c|c|c|}
\hline \multirow[t]{2}{*}{ Approach } & \multicolumn{2}{|l|}{ Mean (SD) } & \multicolumn{2}{|l|}{$95 \% \mathrm{Cl}$} & \multirow[t]{2}{*}{$P$ value } \\
\hline & Anterior & Lateral & Anterior & Lateral & \\
\hline \multicolumn{6}{|c|}{ XSMFA functional index } \\
\hline Preoperative & $35.2(16.1)$ & $40.5(16.0)$ & 31.4-38.6 & $36.3-43.7$ & $0.053^{\mathrm{a}}$ \\
\hline 6 weeks & $21.2(14.2)$ & $28.5(15.9)$ & $17.8-24.2$ & $23.7-32.3$ & $0.026^{\mathrm{a}}$ \\
\hline 3 months & $12.7(12.5)$ & $18.8(16.1)$ & $9.2-14.8$ & $13.7-22.3$ & $0.023^{\mathrm{a}}$ \\
\hline 6 months & $11.6(12.1)$ & $15.8(15.4)$ & $8.3-13.7$ & $10.7-19.3$ & $0.094^{\mathrm{a}}$ \\
\hline 12 months & 10.3(13.0) & $15.1(16.3)$ & 7.3-13.3 & 10.5-19.5 & $0.040^{\mathrm{a}}$ \\
\hline \multicolumn{6}{|c|}{ XSMFA bother index } \\
\hline Preoperative & $48.7(20.5)$ & $53.0(17.9)$ & $43.4-52.6$ & $48.8-57.2$ & $0.126^{\mathrm{a}}$ \\
\hline 6 weeks & $26.6(19.8)$ & $33.0(18.3)$ & $21.6-30.5$ & $28.1-37.9$ & $0.055^{\mathrm{a}}$ \\
\hline 3 months & $19.8(17.0)$ & $33.0(18.1)$ & $15.2-22.9$ & $28.1-37.9$ & $0.099^{\mathrm{a}}$ \\
\hline 6 months & $16.8(15.8)$ & $25.1(17.9)$ & $12.4-19.6$ & $20.0-30.0$ & $0.149^{\mathrm{a}}$ \\
\hline 12 months & $15.8(18.0)$ & $21.7(19.6)$ & $10.8-19.1$ & $9.6-20.4$ & $0.056^{\mathrm{a}}$ \\
\hline \multicolumn{6}{|l|}{ T25-FW (s) } \\
\hline Preoperative & $22.4(5.2)$ & $24.0(3.9)$ & $20.8-23.2$ & $23.1-24.9$ & $0.193^{\mathrm{a}}$ \\
\hline 6 weeks & $21.3(6.3)$ & $22.0(4.2)$ & $19.6-22.4$ & $20.0-23.1$ & $0.385^{\mathrm{a}}$ \\
\hline 3 months & $18.5(3.7)$ & $19.4(3.8)$ & $17.2-18.8$ & $17.0-19.0$ & $0.291^{\mathrm{a}}$ \\
\hline 6 months & $18.3(4.1)$ & $19.9(5.5)$ & $17.1-18.9$ & $17.5-20.5$ & $0.040^{\mathrm{a}}$ \\
\hline 12 months & $18.1(3.4)$ & $19.8(4.6)$ & $17.2-18.8$ & $17.7-20.3$ & $0.046^{\mathrm{a}}$ \\
\hline \multicolumn{6}{|l|}{ Activity VAS } \\
\hline Preoperative & $5.0(0.8)$ & $4.9(0.8)$ & $4.8-5.2$ & $3.8-4.2$ & $0.461^{a}$ \\
\hline 6 weeks & $6.9(0.7)$ & $6.8(0.6)$ & $5.8-6.2$ & $5.8-6.2$ & $0.031^{\mathrm{a}}$ \\
\hline 3 months & $7.3(0.8)$ & $6.9(0.5)$ & $6.8-7.2$ & $5.9-6.1$ & $0.080^{\mathrm{a}}$ \\
\hline 6 months & $7.3(0.7)$ & $6.9(0.7)$ & $6.8-7.2$ & $6.7-7.1$ & $0.223^{\mathrm{a}}$ \\
\hline 12 months & $7.5(0.6)$ & $7.0(0.7)$ & $6.9-7.1$ & $6.8-7.2$ & $<0.001^{\circ}$ \\
\hline \multicolumn{6}{|c|}{ Walking distance (m) } \\
\hline 12 months & $6435(4260)$ & 5125 (3868) & $5458-7412$ & $4053-6197$ & $0.045^{\mathrm{a}}$ \\
\hline \multicolumn{6}{|l|}{ SF-36 PCS } \\
\hline Preoperative & $27.4(8.2)$ & $25.6(8.7)$ & $25.5-28.8$ & $23.0-27.0$ & $0.152^{a}$ \\
\hline 6 weeks & $39.1(9.7)$ & $34.8(9.8)$ & $36,8-41,2$ & $31.4-36.6$ & $0.004^{\mathrm{a}}$ \\
\hline 3 months & $44.6(9.2)$ & $40.7(10.1)$ & $41.9-46.1$ & $37.3-42.7$ & $0.031^{\mathrm{a}}$ \\
\hline 6 months & $46.0(10.0)$ & $42.7(5.6)$ & $43.7-48.3$ & $40.5-43.6$ & $0.042^{\mathrm{a}}$ \\
\hline 12 months & $47.5(9.9)$ & $42.9(11.9)$ & $44.7-49.3$ & $40.1-43.9$ & $0.017^{\mathrm{a}}$ \\
\hline \multicolumn{6}{|l|}{ SF-36 MCS } \\
\hline Preoperative & $57.2(8.5)$ & $56.3(9.2)$ & $55.1-58.9$ & $53.9-58.1$ & $0.405^{\mathrm{a}}$ \\
\hline 6 weeks & $58.1(8.7)$ & $59.3(6.6)$ & $56.0-60.0$ & $57.2-60.8$ & $0.465^{\mathrm{a}}$ \\
\hline 3 months & $56.0(9.2)$ & $56.7(8.3)$ & 53.9-58.1 & $53.8-58.2$ & $0.774^{\mathrm{a}}$ \\
\hline 6 months & $56.0(10.0)$ & $55.8(7.2)$ & $53.7-58.3$ & $53.0-57.0$ & $0.670^{a}$ \\
\hline 12 months & $55.0(9.8)$ & $56.2(6.9)$ & $52.8-57.3$ & $54.1-57.9$ & $0.714^{\mathrm{a}}$ \\
\hline
\end{tabular}

$S D$ standard deviation, $\mathrm{Cl}$ confidence interval

a Mann-Whitney-U test

the discriminative ability oft the HHS is impaired having a limited number of challenging items thus resulting in a ceiling effect [23]. Consequently, the patients who underwent THA by direct anterior MIS show a better functionality while the level of impairment is similar as in the lateral group 1 year after surgery. This is also reflected in the results of the SF-36 physical component score. 
Table 8 Radiographic analysis of cup placement; surgery related complications

\begin{tabular}{lll}
\hline Measure & Anterior & Lateral \\
\hline Mean inclination $\left(^{\circ}\right)$ & $\begin{array}{l}38.6(\text { SD 5.7) } \\
1 \text { (aseptic } \\
\text { loosening, 1.4\%) }\end{array}$ & 40.28 (SD 6.2) \\
Exchange of parts & $3(4.1 \%)$ & 0 \\
$\begin{array}{l}\text { Persistent lateral femoral } \\
\text { cutaneous nerve paraesthesia }\end{array}$ & 0 & 1 \\
Joint dislocation & $2(2.7 \%)$ & $3(6 \%)$ \\
Leg length discrepancy $>1 \mathrm{~cm}$ & $1(1.4 \%)$ & $1(2 \%)$ \\
Trendelenburg &
\end{tabular}

The StepWatch ${ }^{\mathrm{rm}}$ Activity Monitor represents an objective method of taking measurement. The results obtained with the SAM differed significantly between both cohorts. A comparison of these outcomes with previous literature reports proves difficult as a variety of devices were applied to record patient activity in the past. These include mechanical pedometers or traditional accelerometer-based step counting modalities. Furthermore, the periods of patient observation were greatly varying [24]. Nevertheless, the obtained study results correspond well with previously published patient activity levels after THA [25-27]. These outcomes are corroborated by the T25-FW measurements and the determined maximum walking distance at final follow up 12 months after surgery (Table 2).

We observed a higher incidence of varus positions in the DAA group, which was, however, not statistically significant but is a generally known phenomenon [28].

Moreover, a palsy rate of the lateral femoral cutaneous nerve (LCFN) of $4.1 \%$ was seen using the DAA although even higher incidences are described (14.8\%) [29, 30]. The LCFN is a sensory nerve and supplies the anterior and lateral thigh. Its anatomic location varies greatly [31]. As a result, the LCFN is generally prone to injury utilizing a DAA. Persistent neuralgias were, however, not observed.

Joint dislocation after THA remains an unsolved problem. With the anterior approach rates of approximately $0.6-1.6 \%$ [32] are to be expected. In our study, one patient was diagnosed with a dislocated hip in the lateral group while no dislocation occurred in the DAA group.

Notably, one main advantage of the DAA over the lateral approach is that the gluteus tendons/muscles are left unharmed [33, 34]. With lateral approaches, on the other hand, gluteal insufficiency is observed regularly [35]. It was, however, observed in one study patient in each group.

Our study has several limitations. Only $21.5 \%$ of individuals found to be eligible for this study were enrolled. This could potentially lead to sampling bias. Due to patient loss to follow-up the possibility of an inadequate sample size must be considered, especially in regards to the lateral group. Another factor to criticise might be the strict set of exclusion criteria defined what might have influenced the results of both study groups.

Despite the above-mentioned limitations, we conclude that the minimally invasive DAA leads to similar or even superior clinical short and mid-term outcomes when compared to the lateral transgluteal approach.

\section{Conclusions}

THA in general significantly increases patients' activity, functionality and general physical health. After 1 year our outcomes show that THA through the direct anterior approach results in a higher patient activity compared to THA utilizing a transgluteal lateral approach while no differences regarding hip function as represented by the HHS are evident.

\section{Abbreviations}

ASA: American Society of Anesthesiologists; DAA: Direct anterior approach; HHS: Harris Hip Score; LFCN: Lateral femoral cutaneous nerve; MCS: Mental component score; PCS: Physical component score; SAM: Stepwatch ${ }^{\text {TM }}$ Activity Monitor; SF-36: Short Form 36; T25-FW: Timed 25 m foot walk; THA: Total hip arthroplasty; VAS: Visual analogue scale; XSMFA: The extra short musculoskeletal functional assessment questionnaire

\section{Acknowledgements}

The authors thank Rolf Mickler-Strauch for his assistance with the statistical analysis of the generated data.

\section{Funding}

The study was financially supported by the Deutsche Arthrose-Hilfe (Grant P178-A49-Eulert-EP2nöth3-hüfte-opll-156 k-2008-12 and P235-A284-RudertEP2-nöth1-hüfte-op-II-67 k-2001-12). The funding body was not involved in collection, analysis, and interpretation of data and in writing the manuscript.

\section{Availability of data and materials}

The datasets used and analysed during the current study are available from the corresponding author on reasonable request.

\section{Authors' contributions}

JCR was responsible for data collection, interpretation and manuscript preparation. EVR, FR, TR, JH and JK assisted with patient follow up after demission, data acquisition and analysis, and drafting the manuscript. LR, UN and MR were involved in hip replacement surgery, assisted with drafting the manuscript and figure preparation while MR was furthermore responsible for final proof reading. All authors read and approved the final manuscript.

\section{Ethics approval and consent to participate}

The study was approved by the ethics committee of the medical faculty of the University of Würzburg (approval number 72/11) and written consent was obtained from all individual participants included.

\section{Consent for publication}

Not applicable.

\section{Competing interests}

The authors declare that they have no competing interests.

\section{Publisher's Note}

Springer Nature remains neutral with regard to jurisdictional claims in published maps and institutional affiliations. 
Received: 3 February 2018 Accepted: 14 June 2018

Published online: 19 July 2018

\section{References}

1. Khanduja V. Total hip arthroplasty in 2017 - current concepts and recent advances. Indian J Orthop. 2017:51:357-8.

2. Mjaaland KE, Svenningsen S, Fenstad AM, Havelin LI, Furnes O, Nordsletten L. Implant survival after minimally invasive anterior or anterolateral vs. conventional posterior or direct lateral approach: an analysis of 21,860 Total hip arthroplasties from the Norwegian arthroplasty register (2008 to 2013). J Bone Joint Surg Am. 2017:99:840-7.

3. Goebel S, Steinert AF, Schillinger J, Eulert J, Broscheit J, Rudert M, Noth U. Reduced postoperative pain in total hip arthroplasty after minimal-invasive anterior approach. Int Orthop. 2012;36:491-8.

4. Chimento GF, Pavone V, Sharrock N, Kahn B, Cahill J, Sculco TP. Minimally invasive total hip arthroplasty: a prospective randomized study. J Arthroplasty. 2005;20:139-44.

5. Noth U, Nedopil A, Holzapfel BM, Koppmair M, Rolf O, Goebel S, Eulert J, Rudert M. Minimally invasive anterior approach. Orthopade. 2012;41:390-8.

6. Eskelinen A. Minimally Invasive THA: Where are we now and where are we heading?: commentary on an article by Ciara Stevenson, FRCS, et al.: "minimal incision Total hip arthroplasty. A concise follow-up report on functional and radiographic outcomes at 10 years". J Bone Joint Surg Am. 2017;99:e109.

7. Rachbauer F. Minimally invasive total hip arthroplasty via direct anterior approach. Orthopade. 2005:34:1103-4. 1106-1108, 1110

8. Bauer R, Kerschbaumer F, Poisel S, Oberthaler W. The transgluteal approach to the hip joint. Arch Orthop Trauma Surg. 1979;95:47-9.

9. Mudge S, Taylor D, Chang O, Wong R. Test-retest reliability of the StepWatch activity monitor outputs in healthy adults. J Phys Act Health. 2010;7:671-6.

10. Efird J. Blocked randomization with randomly selected block sizes. Int J Environ Res Public Health. 2011:8:15-20.

11. Harris WH. Traumatic arthritis of the hip after dislocation and acetabular fractures: treatment by mold arthroplasty. An end-result study using a new method of result evaluation. J Bone Joint Surg Am. 1969;51:737-55.

12. Wollmerstedt $\mathrm{N}$, Glatzel M, Kirschner S, Schneider J, Faller H, Konig A. Comparative analysis of patient-centered outcome of total hip and knee arthroplasty. Z Orthop Ihre Grenzgeb. 2006;144:464-71.

13. Garratt A, Schmidt L, Mackintosh A, Fitzpatrick R. Quality of life measurement: bibliographic study of patient assessed health outcome measures. BMJ. 2002;324:1417.

14. Johnston RC, Fitzgerald RH Jr, Harris WH, Poss R, Muller ME, Sledge CB. Clinical and radiographic evaluation of total hip replacement. A standard system of terminology for reporting results. J Bone Joint Surg Am. 1990;72:161-8.

15. Weber M, Benditz A, Woerner M, Weber D, Grifka J, Renkawitz T. Trainee surgeons affect operative time but not outcome in minimally invasive Total hip arthroplasty. Sci Rep. 2017;7:6152

16. Stevenson C, Ogonda L, Blaney J, Dennison J, O'Brien S, Beverland D. Minimal incision Total hip arthroplasty: a concise follow-up report on functional and radiographic outcomes at 10 years. J Bone Joint Surg Am. 2017;99:1715-20

17. Schwarze M, Budde S, von Lewinski G, Windhagen H, Keller MC, Seehaus F, Hurschler C, Floerkemeier T. No effect of conventional vs. minimally invasive surgical approach on clinical outcome and migration of a short stem total hip prosthesis at 2-year follow-up: a randomized controlled study. Clin Biomech. 2018:51:105-12.

18. Reichert JC, Volkmann MR, Koppmair M, Rackwitz L, Ludemann M, Rudert M, Noth U. Comparative retrospective study of the direct anterior and transgluteal approaches for primary total hip arthroplasty. Int Orthop. 2015; 39:2309-13.

19. Parvizi J, Restrepo C, Maltenfort MG. Total hip arthroplasty performed through direct anterior approach provides superior early outcome: Results of a Randomized, Prospective Study. Orthop Clin North Am. 2016;47:497-504.

20. Meermans G, Konan S, Das R, Volpin A, Haddad FS. The direct anterior approach in total hip arthroplasty: a systematic review of the literature. Bone Joint J. 2017;99-B:732-40.

21. Laffosse JM, Chiron P, Molinier F, Bensafi H, Puget J. Prospective and comparative study of the anterolateral mini-invasive approach versus minimally invasive posterior approach for primary total hip replacement. Early results. Int Orthop. 2007;31:597-603.
22. Wollmerstedt N, Faller H, Ackermann H, Schneider J, Glatzel M, Kirschner S, Konig A. Evaluation of the extra short musculoskeletal function assessment questionnaire XSMFA-D in patients with musculoskeletal disorders and surgical or medical in-patient treatment. Rehabilitation. 2006;45:78-87.

23. Wamper KE, Sierevelt IN, Poolman RW, Bhandari M, Haverkamp D. The Harris hip score: do ceiling effects limit its usefulness in orthopedics? Acta Orthop. 2010;81:703-7.

24. Shepherd EF, Toloza E, McClung CD, Schmalzried TP. Step activity monitor: increased accuracy in quantifying ambulatory activity. J Orthop Res. 1999;17: 703-8.

25. Wollmerstedt $\mathrm{N}$, Noth $\mathrm{U}$, Ince A, Ackermann H, Martell JM, Hendrich C. The daily activity questionnaire: a novel questionnaire to assess patient activity after total hip arthroplasty. J Arthroplasty. 2010;25:475-80. e471-473

26. Naal FD, Impellizzeri FM. How active are patients undergoing total joint arthroplasty?: a systematic review. Clin Orthop Relat Res. 2010:468:1891-904.

27. Silva M, McClung CD, Dela Rosa MA, Dorey FJ, Schmalzried TP. Activity sampling in the assessment of patients with total joint arthroplasty. J Arthroplast. 2005;20:487-91.

28. Beverland D. Approaches. In: Vidalain J-P, TAS S, Beverland D, et al., editors. The Corail ${ }^{\oplus}$ hip system. Berlin Heidelberg, Heidelberg: Springer; 2011. p. 193-216. https://doi.org/10.1007/978-3-642-18396-6_6.

29. Bhargava T, Goytia RN, Jones LC, Hungerford MW. Lateral femoral cutaneous nerve impairment after direct anterior approach for total hip arthroplasty. Orthopedics. 2010;33:472.

30. Smith TO, Blake V, Hing CB. Minimally invasive versus conventional exposure for total hip arthroplasty: a systematic review and meta-analysis of clinical and radiological outcomes. Int Orthop. 2011;35:173-84.

31. Hoberg M, Rudert M, Tillmann B. Minimally invasive hip arthroplasty - what must be spared? Orthopade. 2012;41:338-45.

32. Yi C, Agudelo JF, Dayton MR, Morgan SJ. Early complications of anterior supine intermuscular total hip arthroplasty. Orthopedics. 2013;36:e276-81.

33. Cadossi M, Sambri A, Tedesco G, Mazzotti A, Terrando S, Faldini C. Anterior approach in Total hip replacement. Orthopedics. 2017:40:e553-6.

34. Rykov K, Reininga IH, Knobben BA, Sietsma MS, Ten Have BL. The design of a randomised controlled trial to evaluate the (cost-) effectiveness of the posterolateral versus the direct anterior approach for THA (POLADA - trial). BMC Musculoskelet Disord. 2016;17:476.

35. Zahiri CA, Schmalzried TP, Szuszczewicz ES, Amstutz HC. Assessing activity in joint replacement patients. J Arthroplast. 1998;13:890-5.

Ready to submit your research? Choose BMC and benefit from:

- fast, convenient online submission

- thorough peer review by experienced researchers in your field

- rapid publication on acceptance

- support for research data, including large and complex data types

- gold Open Access which fosters wider collaboration and increased citations

- maximum visibility for your research: over $100 \mathrm{M}$ website views per year

At BMC, research is always in progress.

Learn more biomedcentral.com/submissions 